\title{
HET ADRES AAN DEN RAAD VAN ROTTERDAM OVER DE STEDELIJKE BELASTINGEN.
}

Aan den Gcmeente-Raad van Rotterdam is een Adres ingediend door den Heer van Teylingen van Kamerix, Tresorier der stad, welk adres, een voorstel behelst, om, ten opzigte van Rotterdam, een uitzondering te maken in de bepalingen der Gemeentewet omtrent gemeente-belastingen.

Het geheel is een verdediging van accijnsen als een middel van plaatselijke inkomsten, en de schrijver meent dat een ruim gebruik van dit middel, en eene spaarzame toepassing van directe heffingen, gedurende een reeks van jaren de zegenrijkste vruchten hebben gedragen, zoodat eene wijziging in dat weldadige stelsel niet anders dan noodlottig zoude kunnen zijn.

Aan het onderzoek van een paar hoofdpunten van dit geschrift willen wij eenige regels wijden.

Het adres, ook in druk uitgekomen, vangt aan met eene schets van de finantieele geschiedenis ran Rotterdam, voor zoover de gemeente-belastingen betreft.

Daaruit blijkt dat de indirecte belastingen gaandeweg de grootste plaats in de middelen hebben ingenomen.

Van 1808 tot 1811 was de opbrengst der directe belastingen en der indirecte op het stedelijk Budget nagenoeg gelijk.

Van 1811 af bespeurt men een doorgaande toeneming van de accijnsen, slechts met een korte tusschenpoozing van 1814 tot 1śl6, gedurende welke men weder tot de directe heffingsmiddelen zijn toevlugt nam, doch zonder het gewenscht gevolg.

"Sedert 1817, en alzoo gedurende 35 achtereenvolgende jaren," zoo vervolgt de schrijver, "heeft dus het stelsel van indirecte be"lasting of impost op voorwerpen van verbruik, geregeerd. - Di$*$ recte heffingen, i. e. omslagen gegrond op de huurwaarde van 
"bewoonde panden, zijn slechts nu en dan, als buitengewone midv delen geheven, om bestaande te korten te dekken.

In die 35 jaren heeft Rotterdam gebloeid, en zijn er in de stad aanzienlijke en kostbare verbeteringen daargesteld: de uitlegging der stad, stichting van nieuwe gebouwen, verbreeding van straten, aanleg van begraaf plaats en wandelwegen, enz. Buitendien is er voor ruim een millioen schuld gëamortiseerd, en sindien "men dit nagaat," zegt de schrijver, "dan is het onmogelijk een nbelastingstelsel te verwerpen, dat zulke groote dingen heeft te neeeg gebragt."

Met de nieuwe Rotterdamsche Courant zijn wij van oordeel dat hier zonder eenigen grond tot de conclusie is gekomen, dat die kostbare werken en nuttige daarstellingen het gevolg zijn van het stelsel van Indirecte Belasting: zoodanig gevoelen hadden wij, zelfs door de ijverigste voorstanders, nog nimmer hooren uiten.

Veeleer zouden wij daarvoor in de plaats willen stellen:

"Indien Rotterdam, niettegenstaande zooveel jaren van indirecte heffingen, bloeit, en voortdurend over vele middelen kan beschikken, dan voert dit een sterk bewijs met zich, dat juist deze stad uitnemend geschikt is voor het voordeeliger stelsel van directe heffing, dat, hoezeer algemeen erkend in beginsel het voordeeligst te zijn, slechts weerzin ontmoet in de toepassing, wanneer de mindere welvaart der ingezetenen de betaling der betrekkelijk aanzienlijke belastingsommen, in eens of in bepaalde termijnen, bezwarend maakt."

Doch volgen wij de verdediging van het accijnsen-systeem in het algemeen.

De schrijver van het adres doet eene verwijzing (pag. 16) naar het Engelsche belasting-stelsel, als aan indirecte belasting de voorkeur gevende.

„In Engeland schijnen aan de gemeenten meer speciaal de - directe belastingen overgelaten te zijn, terwijl de grondlasten door whet rijk geheven, zeer matig zijn, doch de indirecte belastinngen voor ruim 1000 millioen op de rijksbegrooting zijn uitgestrokken, en alzoo voor het rijk het belastingstelsel verreweg "tot de indirecte overhelt."

Deze 1000 millioen an indirecte rijksbelasting schijnt eene vergissing, aangezien het geheele budget niet meer dan 600 millioen guldens bedraagt.

De budgets van Engeland naziende, bevindt men daar, in groote cijfers, de middelen van inkomst aldus: 
Indirecte rijks Belastingen. nirca

Directe rijks Belastingen.

Douanes $\{\mathbf{2 0 . 0 0 0 . 0 0 0 ~ o f ~} f \mathbf{2 4 0 . 0 0 . 0 0 0 0}$ Grondbelasting

Accijusen " 14.000 .000 " " 168.000 .000 en personeel $\mathbf{4} 4.600 .000$ of $f \mathbf{4 8 . 0 0 0 . 0 0 0}$

Zegel "6.000.000" 72.000000 Income-tax " 5.000 .000 " 60.000 .000

$\{40.000 .000$ of $f 480.000 .000$

\pm 9.000 .000 of $f 108.000 .000$

Het totaal bedrag der indirecte rijksbelastingen is dus ongeveer de helft van het in het adres opgegeven cijfer; eene zeer verklaarbare vergissing, indien Fransche werken zijn geraadpleegd, welligt het bedrag aan franken opgevende: - en die ook ter zake weinig afdoet.

De schrijver verwijst op het geringe bedrag der grondbelasting in Engeland - dit is waar, indien men enkel den naam "grondbelasting" in aanmerking neemt. -

Maar de lasten op den grondeigendom zijn veel grooter dan het cijfer onder het hoofd land tax op het rijksbudget voorkomende. Want

$a$. het geheele bedrag der armentax, dikwijls $f 60$ à $f 70$ millioen, of meer, voor Engeland en Wallis alleen, is een last die uitsluitend op de landerijen berust. - Bovendien

b. een groot gedeelte der overige gemeente-uitgaven, voor wegen, bruggen, politie-kosten, wordt gevonden door verschillende omslagen op gebouwde en ongebouwde eigendommen. - (en voor deze twee rubrieken $a$ en $b$ wordt in' het geheele rijk circa $f 140$ millioen jaarlijks opgebragt.)

c. dragen de grondeigenaars nog, qua grondeigenaars, in de $\mathrm{Ta}$ bel A. der inkomsten-belasting: zij alleen betalen nagenoeg de helft van de $f 60$ millioen dezer directe belasting.

Buitendien moet men hierbij in aanmerking nemen, dat vele grondlasten vroeger afgekocht zijn, zoodat het kapitaal der jaarlijksche belasting eens, vooral an het land is betaald - hiermede is dus de grond bezwaard geworden, doch de renten van die afkoopingsom komen natuurlijk niet jaarlijks als baten der schatkist op het budget voor. -

Deze bijzaken moet men in het oog houden, wanneer men uit een overzigt van het Engelsche rijks-budget de conclusie zou willẹn maken, dat de landerijen aldaar zoo weinig belast zijn, en dat men er in het algemeen de voorkeur zoude gegeven hebben aan de indirecte belastingen. $(\dagger)$

(*) Zie omtrent de Engelsche rijksmiddelen: Economist 1852 pag. 162.

(†) Zie Indirecte Belastingen enz. pag. 89. 
Fr is overigens een zeer gewigtige beschouwing die, - het worde hier met alle bescheidenheid door ons aangemerkt, - veel te dikwijls uit het oog wordt verloren. - Het is dat men in het algemeen al wat indirecte belasting, of liever al wat accijns is, onder hetzelfde licht wil beschouwen en onder een en dezelfde cathegorie brengt, ter veroordeeling of verdediging. Zoo wordt ook hier weder, als vergelijking van de budgets van twee verschillende landen, als maatstaf der vergelijking aangenomen, welk bedrag in elk door "de indirecte belastingen" wordt ingenomen.

Is dit een billijke maatstaf? - Geenzins - reeds rroeger (*) bebben wij getracht hierop de aandacht te vestigen. Alles hangt af van de voorwerpen waarop de verbruikbelasting rust. -

Wel is het waarheid, dat de handel, het vervoer van elk artikel, op zich zelf beschouwd, evenzeer door de formaliteiten, enz. zal benadeeld worden, en dat dus, uitsluitend net het oog op de producteurs der onderscheiden artikelen zelve, de gevolgen der verbruikbelasting dezelfde mogen zijn; - maar voor de millicenen verbruikers maakt het een ontzaggelijk onderscheid of de kunstmatige duurte een voorwerp treft van levensbehoefte of van weelde. -

Zoude men b. v. in gemoede durven beweren dat het voor een volk hetzelfde is, of een zeker bedrag aan indirecte belasting wordt verkregen door kunstmatige duurte van brood, of door kunstmatige dunrte van thee of tabak? - Het antwoord zal indedaad niet moeijelijk wezen. Toch komen beide in dezelfde classificatie van »verbruikbelasting:" - dat men zich dus niet vergenoege met namen tegen namen te vergelijken, maar steeds in het oog houde de gevolgen op den algemeenen arbeid, op de welvaart. -

Behalve het verschil dat er bij eene beoordeeling van verbruikbelasting is te maken, angaande de voorwerpen die getroffen worden, namelijk, of een voorwerp van noodzakelijkheid of weelde getroffen wordt, een verbruik tot louter genot (b. v. tabak), of een verbruik tot weder-voortbrenging (het brood), maakt het een groot verschil hoe de belasting op een voorwerp geïnd wordt: - wordt het voorwerp welks verbruik belast wordt, binnenslands en op vele plaatsen voortgebragt, dan is er een aanzienlijk toezigt, eene voortdurende bewaking noodig op fabriekaadje, op uitslag en vervoer menigvuldige reglementen, en daardoor telkens grooter gelegenheid en grooter aanloksels tot sluiken, zijn er het onvermijdelijk gevolg van. - Maar anders is het, indien de belasting een voorwerp

(*) Indirecte Belasting pag. 91 . 
treft dat alleen buiten 's lands wordt voorgebragt, zoo als thee, koffij, en, indien men de inlandsche kultuur kan verbieden, de tabak - dan is alles gevonden met een enkel regt bij den invoer te doen betalen, en het voortdurende toezigt op binnenlandsch vervoer is niet meer noodig. $\mathrm{Er}$ is dus een ontzettend verschil tusschen een rijksaccijns op zoodanige wijze geheven, en plaatselijken accijns die elken stap van den. vervoer-handel belemmert, ofschoon beide ook weer onder de algemeene rubriek "verbruikbelasting" kun. nen gebragt worden. Hierbij bedenke men dat formaliteiten en moeijelijkheden voor handelaar of fabrikant niet daarom zoo nadeelig zijn, omdat deze daardoor meer lasten hebben: - Ware er alleen dit aan verbonden, dan ware de zaak voorwaar van minder belang : - maar men onthoude dat formaliteit en moeite voor den producteur onfeilbaar met zich voert v verhooging van prijs voor den verbruiker ;" - de voortbrenger arbeidt, - hij doet moeite en voorschotten, en dat alles moet hij vergoed vinden in den eindprijs dien hij bekomt. -

Hoe meer moeite en hoe meer voorschot men nu aan de productie verbindt, hoe duurder men den eindprijs maakt, zonder dat die verhooging, op verre na, geheel in de schatkist komt: de schatkist krijgt maar het batig saldo dat geïnd wordt, een gedeelte van het voorschot: de rente van het roorschot, de risico's van verlies, de vernaauwing van concurrentie, de winst van den sluiker, ziedaar menigvuldige prijsverhooging, welke de verbruiker betaalt, en waarvan de schatkist niets bekomt.

Deze beschouwingen, die thans zoo eenvoudig schijnen, nu de latere onderzoekingen der wetenschap de zaak meer in een duidelijk licht hebben gesteld, schijnen reeds als van zelve het Engelsche volk geleid te hebben, hierin

$a$. dat zij de plaatselijke inkomsten geheel door directe middelen hebben geheven, alzoo het geheele binnenlandsche vervoer vrij latende, in plaats van hun land dat alleen door vrij verkeer kan bloeijen, door honderden van inwendige douauen te verzwakken, en één groote natuurlijke markt, in een menigte kunstmatig kleine markten te verdeelen.

b. door die verbruikbelastingen die tot heffing der rijks uitkomsten noodzakelijk waren, zooveel mogelijk te doen drukken op voorwerpen die niet tot levensbehoeften behooren, die niet tot productie noodzakelijk zijn, of die, van buiten af wordende ingevoerd, slechts het toezigt bij de douanen-linie vereischen, om aldaar, de dikwijls zeer hooge regten te voldoen.

Len enkele opnoeming van de voorwerpen die in de twee hier 
bedoelde rijken door verbruikbelastingen getroffen worden, zal dit verschil van systeem duidelijker doen uitkomen. -

$$
\text { Nederland. Engeland. }
$$

$\begin{array}{lll}\text { Brood } & \text { belast. } & \text { vrij } \\ \text { Vleesch } & \text { belast } & \text { vrij } \\ \text { Zout } & \text { belast } & \text { vrij } \\ \text { Turf } & \text { belast } & \text { vrij } \\ \text { Steenkolen } & \text { belast } & \text { vrij } \\ \text { Azijn } & \text { belast } & \text { vrij } \\ \text { Zeep } & \text { belast } & \text { belast } \\ \text { Suiker } & \text { belast } & \text { belast } \\ \text { Bier } & \text { belast } & \text { belust } \\ \text { Wijn } & \text { belast } & \text { belast } \\ \text { Gedistilleerd } & \text { belast } & \text { belast } \\ \text { Papier } & \text { vrij } & \text { belast } \\ \text { Thee } & \text { vrij } & \text { belast } \\ \text { Koffij } & \text { vrij } & \text { belast } \\ \text { Tabak } & \text { vrij } & \text { belast (*) }\end{array}$

Ofschoon er in het adres, en ook in dit artikel zelf, slechts voornamelijk sprake is van gemeente-belastingen, zoo is deze kleine uitwijding echter direct op de zaak betrekkelijk; omdat de Heer $\nabla$. T. in de groote mate der indirecte belastingen op het Engelsche rijks-budget, (of liever in de aanzienlijke opbrengst van die heffingen aldaar) bewijzen meent te vinden voor een ruim aandeel der accijnsen in onze plaatselijke belastingen.

Om dat te waarderen, moesten wij het aangehaalde sijsteen iets nader onderzoeken.

(*) Met dit belasten van minder noodzakelijke voorwerpen, waarvan toch een uitgestrekt verbruik bestaat, is men dan ook gansch niet schrootmvallig, zoodat dikwijls de belasting alleen, 3 a 4 maal de volle waarde van het voorwerp bedraagt.

De napolgende cijfers der opbrengsten ran 1851 kunnen het belangrijke dezer heffingen antoonen :

Opbrengst der belasting op

\begin{tabular}{|c|c|c|c|c|c|c|}
\hline het & ruik & & Gedistilleerd & f 8.555 .573 & of $f$ & 102.666 .876 \\
\hline & , & ", & Thee & " 5.900 .624 & $"$ & 70.807 .488 \\
\hline & 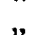 & * & Mout en Hop & 5.461 .587 & " & 65.539 .044 \\
\hline & 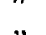 & ; & Tabak & 4.466 .468 & $n$ & 53.597 .616 \\
\hline & $\because$ & ", & Suiker & $" 4.159 .038$ & $n$ & 49.908 .456 \\
\hline & & & & & & 42.519 .480 \\
\hline
\end{tabular}

meer dan de helft van het geheele Budget wordt dus enkel hierdoor betaald. 
Tot staving van zijn gevoelen beroept de Heer $\nabla$. T. zich verder op het verslag der Belgische commissie, in 1847 benoemd, om het vraagstuk eener afschaffing der stedelijke accijnsen in België grondig te onderzoeken, en daaromtrent rapport uittebrengen.

Wij meenen echter, dat de zinsneden in het Rott: adres aangehaald, met het rapport dier commissie in geene betrekking

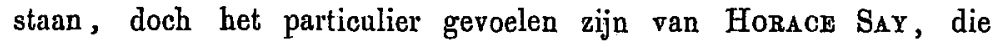
angaande dit onderwerp, alstoen gelijktijdig èn in Frankrijk èn in België ter sprake, een artikel uitgaf in het Journal des Economistes van Sept. 1848. - (Zie Parijsche uitgaaf: pag. 130, sqq.)

Eenige beschouwingen van dezen bekenden staathuishoudkundige gaan vooraf aan de beoordeeling van het rapport der Belgische commissie, en in dat stuk van HoracE $\mathrm{S}_{A Y}$, vinden wij de medegedeelde citaten vervat - (p. 131 en 132), waarvan echter de strekking naar onze meening, niet zoo geheel in den geest ran den Heer v. T. is, als men door de lezing van het adres zou kunnen opvatten.

Op pag. 10 van het adres, sprekende van het stelsel dat te Rotterdam in de laatste 35 jaren gevigeerd heeft, wordt gezegd dat de indirecte middelen steeds als normale middelen van inkomsten zijn gebezigd en uitgebreid, terwijl de directe heffingen meer als builengewone middelen zijn beschouwd. $n \mathrm{Bij}$ toereikendheid "der belastingen op de voorwerpen van verbruik, zijn de omslagen "telkens verminderd, on de personeele omslag in de laatste jaren "geheel weggelaten, in dat beginsel overeenstemmende met de merkv waardige zinsnede voorkomende in een rapport van de commissie in ${ }$ Belgie, wordende daar gezegd:

"Aussi est-il posé en axiome chez les gens de finances, qu'il faut user largement des impots indirects en temps de prospérité, afin de ménager la propriété et pouroir recourir aux contributions directes, lorsque les crises survieunent."

Op Pag. 13 van het adres lezen wij verder: "aan de Belgi"sche commissie is de eerste vraag gedaan: of de octrooijen de "beste middelen zijn, orm in de behoeften der gemeenten te voor"zien? en hoewel dit ontkennend beantwoordende als beginsel, er"kent zij, dat tegen de suppressie onoverkomelijke bezwaren be"staan, en gaan verder voort, de redenen daarvoor optegeven, in "de volgende zinsneden:

"Les contributions indirectes, pour être productives, doivent porter sur les denrées les plus essentielles à la vie: dès lors la charge générale qui en résulte, est proportionnée à la consommation individuelle, 
et non pas aux revenus, ETc. Ce genre de taxe toutefois, venant se confondre avec le prix de la denrée, s'acquittant au jour le jour par fractions minimes, est perçu avec facilité en temps ordinaire, et ce n'est guère qué dans les moments de gène que le contribuable fait entendre de vives reclamations.

$\mathrm{Nu}$ vindt men in het bedoelde betoog van $\mathrm{H}$. SAY (Journal der Economistes, 1848. vol. III, p. 131), deze aangehaalde zinsneden aldus :

Les contributions indirectes, pour être productives, doiveut porter sur les denrées les plus essentielles à la vie; dès lors la charge générale qui en résulte est proportionnée à la consommation individuelle et non pas aux revenus. Il sult de là que cette char̃ge est injustemeut repartie, et constitue un véritabe impôt progressif en sens inverse, c'est-à-dire pesant d'autant plus fortement que le contribuable a moins de revenu pour y faire face. - Ce genre de taxe toutefois, venant se confondre avec le prix de la denrée, s'acquittant au jour le jour, par fractions minimes, est perçu avec facilité en temps ordinaire, et ce n'est gnère que dans les moments de géne que le'contribuable fait entendre de vives reclamations. Aussi est-il passé en axiome chez les gens de finances, qu'il fait user largement des impots indirects en temps de prospérité, afin de ménager le propriété, et pouvoir recourir aux contributions directes lorsque les crises surviennent.

Alzoo leest men achtereenvolgens in het bedoelde stuk van HoRACE $S_{A Y}$, en indien men daardoor de afzonderlijk medegedeelde citaten van het Rotterdamsche adres, in hun verband herstelt, dan bevindt men dat er eene geheel andere waarde aan te hechten is dan zoo als zij in het adres voorkomen - de hier in cursief medegedeelde phrase $(\pi$ suit $d e l \grave{a}$, enz.) is in het citat van het adres weggelaten, doch vervangen door: ETC. - En de laatste hier voorkomende zinsnede (Aussi est-il passé, enz.) wordt op pag. 10 adres voorgesteld, als of het een finantieele regel ware, door ervaring geijkt, en door de Belgische Commissie ter opvolging voorgesteld. -

Door de herlezing van het oorspronkelijke bevindt men dat dit niet het geval is: de ter bevestiging angehaalde zinsneden zijn eenvoudig een constatering van den tegenwoordigen toestand: er wordt eenvoudig verklaart, "hoe men er langzamerhand toe gekomen is om dien gemakkelijken doch bedriegelijken weg te bewandelen." Il est "passé (niet posé) en axiome chez les gens de finance, om verreweg de indirecte belastingen te verkiezen. Dit nu is enkel een herhaling wat de financiers gedaan hebben, het is geenzins goedkeuring van die zienswijze, zoo als trouwens nog meer blijkt nit het onmiddelijk daarop volgende :

„Les emprunts sont pour les gouvernements un moyen de lever par 
anticipation des impôts sur l'svenir, et d'engloutir ainsi annuellement une partio des épargnes individuelles, qui, sans cela, a uraient grossi la masse des capitaux du pays. Les générations futures doivent rester chargées du soin d'en servir les intérets. Ces emprunts ont été singulièrement facilités par l'expédient trouvé dans les contributions indirectes d'en servir les intérets, par le leurre de s caisses d'amortissement, enz.

Door de geheele mededeeling der aangehaalde citaten blijkt het dat zij wezenlijk geen lofspraak op het beginsel van indirecte belasting daarstellen.

Plaatsgebrek verhindert ons om thans het adres nog verder na te gaan. - In de N. Rott. Courant zijn reeds verscheiden der argumenten bestreden, welke wij dus hier achterwege konden laten: daarom hebben wij ons voor het oogenblik bepaald tot de wederlegging van diè wetenschappelijke betoogen, welke de Heer $\mathbf{}$. T. annvoert tot verdediging van het beginsel van plaatselijken accijns op eerste levensbehoeften: een beginsel dat ons voorkomt, onder schoonschijnende beloften, de ongelukkigste gevolgen na zich te sleepen, en dat dus niet met te veel naauwkeurigheid kan worden onderzocht, - vooral thans, nu de herziening der plaatselijke belastingstelsels, door de gemeentewet gevorderd, eene hervorming ten deze opzigte van zelve mede kan voeren. Daarom is het van belang, en van algemeen belang, om de waarde der argumenten te onderzoeken waarmede men de hervorming wil tegenhouden. - Men zegge niet het adres alleen Rotterdam betreft: het beginsel geldt alle gemeenten van het rijk. Is het waar dat Rotterdam in een exceptioneelen toestand rerkeert, zoo als het adres zich uitdrukt, dan is het voorzeker in een exceptioneelen toestand van bloei, in vergelijking met de meeste overigen Nederlandsche steden, - en, een oogenblik verondersteld, dat de ten adresse aangevoerde gronden ingang konden vinden, hetzij bij de wetgeving, hetzij bij de plaatselijke besturen, dan zoude daarin zeker een bewrijs à fortiori zijn voor de aanneming derzelfde beginselen bij de andere gemeenten. Daarom rekenen wij dit onderwerp, vooral in den tegenwoordigen oogenblik, gewigtig. Overigens meenden wij anleiding genoeg te vinden, in de bestrijding van eenigen plaatsen van ons werkje nover Indirecte Belasting," in het Adres poorkomende, om tot deze bijdrage eenige bladzijden van den Economist te besteden.

RED. 